\title{
Heat exchanger design for hot air ericsson-brayton piston engine
}

\author{
P. Ďurčanský ${ }^{1, a}$, R. Lenhard ${ }^{1}$, and J. Jandačka ${ }^{1}$ \\ ${ }^{1}$ University of Žilina, Faculty of mechanical engineering, Department of energy technology, Univerzitna 1, 01026 Žilina, \\ Slovak Republic
}

\begin{abstract}
One of the solutions without negative consequences for the increasing energy consumption in the world may be use of alternative energy sources in micro-cogeneration. Currently it is looking for different solutions and there are many possible ways. Cogeneration is known for long time and is widely used. But the installations are often large and the installed output is more suitable for cities or industry companies. When we will speak about decentralization, the small machines have to be used. The article deals with the principle of hot-air engines, their use in combined heat and electricity production from biomass and with heat exchangers as primary energy transforming element. In the article is hot air engine presented as a heat engine that allows the conversion of heat into mechanical energy while heat supply can be external. In the contribution are compared cycles of hot-air engine. Then are compared suitable heat exchangers for use with hot air EricssonBrayton engine. In the final part is proposal of heat exchanger for use in closed Ericsson-Brayton cycle.
\end{abstract}

\section{Micro-cogeneration unit with nonconventional engine}

As power unit of micro-cogeneration devices are most used gas combustion engines, as fuel is used natural gas. Into the engine is transferred fuel, through combustion we are gaining mechanical work on the output shaft and the heat energy is transferred through cooling system to the cooling heat exchanger. Additionally we may collect thermal energy from the flue gas exchanger. These heat exchangers are then connected in series circuit, where the working medium, usually water, is heated in several stages. Multistage heat recovery increases the overall efficiency of CHP unit and reduces the total cost of fuel. As a possible alternative to the internal combustion engines are unconventional engines. They work with external combustion, or burning fuel does not take place in the working cylinder. This allows, unlike conventional internal combustion engines, control the course of combustion, and therefore its quality, which is reflected in the composition of air pollutants emitted to the atmosphere. The most known hot air engines are Stirling and Ericsson engine. Ericsson engine has posible modification, the Ericsson-Brayton engine. Ericsson engine is also external combustion engine. In contrast to the Stirling engine has two possible alternatives - open and closed [1]. In the case of Stirling engine is immediately apparent dual function regenerator. Regenerator functions as heater and cooler while in Ericssonovho engine cooler and heater are separated. The air is compressed in the compressor, flows through the heat exchanger, and where at constant pressure is receiving heat. Consequently, it is led to the expansion cylinder, which expands adiabatically and is acting work. Part of this work will be used to drive the compressor and part is used as mechanical work to drive an electric generator. As the heat source can be used almost any fuel, as it is the external combustion engine. Fuel is burned in a separate combustion chamber and heat energy is transformed through a heat exchanger to the working media. The working medium in open cycle, mostly dry air, in a closed cycle after each cycle cools in refrigerant heat exchanger, where it gives heat energy and is fed back into the cycle [2]. With use of closed cycle we can improve the efficiency of heating equipment. On the Figure 1 we can see schema of proposed nonconventional micro-cogeneration unit with Ericsson - Brayton hot air engine.

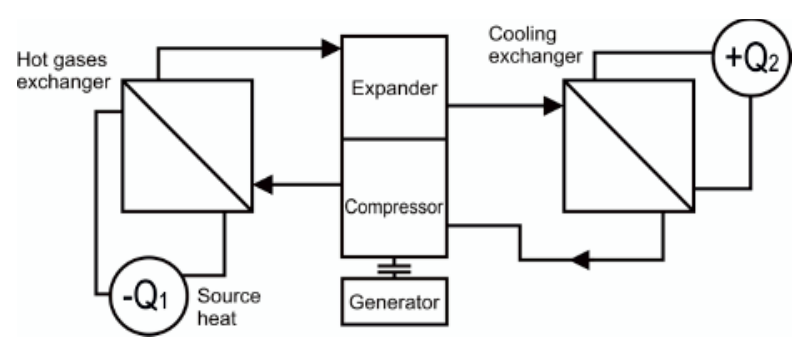

Figure 1. Scheme of microcogeneration unit with EricssonBrayton hot air engine.

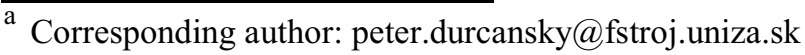


The proposed microcogeneration unit uses two heat exchangers, one is cooler and another is heater. Different purpose sets other requirements on the heat exchangers. The first requirement is to ensure optimal heat transfer between flowing media. The heat transfer is characterized by a heat transfer coefficient. This summary represents the characteristics of the heat exchanger, its layout and the flowing media. Coefficient depends on the characteristics of the media flowing, from the heat capacity, the selected konstruction option and in some cases is significantly influenced by the material used and the heat exchanger. The requirement is that the coefficient is the highest, while respecting the chosen solutions. Further requirements are then asked to compact size exchanger, the total pressure loss and also maintenance options are required.

\section{Heat exchanger design using criterion formula}

As first step we have set the working conditions of the CHP. Our apllication with Ericsson-Brayton hot air engine sets wide range of specifications, not only on the heat exchanger, but also on the whole system. The whole unit should supply energy for household. In the determining of the operating conditions we have preliminary set the highest temperatures from $500{ }^{\circ} \mathrm{C}$ up to $620^{\circ} \mathrm{C}$, according to [3], [5]. In this articles, autors presented highest temperature $600^{\circ} \mathrm{C}$. Another autors [1] have presented systems with different working fluids and also different hot air engine configurations.

Table 1. Ericsson engine configuration

\begin{tabular}{|c|c|c|c|c|}
\hline $\begin{array}{l}\text { Investigato } \\
\mathbf{r}\end{array}$ & $\begin{array}{c}\text { Ericsson } \\
\text { engine } \\
\text { configuratio } \\
\mathbf{n}\end{array}$ & $\begin{array}{l}\text { pressure } \\
\text { ratio }\end{array}$ & $\begin{array}{c}T \\
\max \end{array}$ & $\mathbf{N}$ \\
\hline $\begin{array}{l}\text { Wojewoda } \\
\text { et al. }\end{array}$ & $\begin{array}{l}\text { Pre-heater, } \\
\text { heater and } \\
\text { cooler with } \\
\text { external } \\
\text { combustion, } \\
\text { closed cycle }\end{array}$ & 4,75 & $\begin{array}{c}873- \\
1273 \\
K\end{array}$ & $\begin{array}{c}500- \\
3000 \\
\mathrm{rpm}\end{array}$ \\
\hline Moss et al. & $\begin{array}{l}\text { Recuperator, } \\
\text { open cycle }\end{array}$ & $1-16$ & $\begin{array}{c}1000 \\
- \\
1200 \\
\mathrm{~K}\end{array}$ & $\begin{array}{c}300- \\
2000 \\
\mathrm{rpm}\end{array}$ \\
\hline Bell et al. & $\begin{array}{l}\text { Pre-heater, } \\
\text { combustion } \\
\text { chamber, } \\
\text { internal } \\
\text { combustion, } \\
\text { open cycle }\end{array}$ & $1-20$ & $\begin{array}{c}1300 \\
\mathrm{~K}\end{array}$ & $\begin{array}{c}- \\
\mathrm{rpm}\end{array}$ \\
\hline Lontsi et al. & $\begin{array}{c}\text { Heat } \\
\text { exchanger, } \\
\text { external } \\
\text { combustion, } \\
\text { open cycle }\end{array}$ & 3,6 & $873 \mathrm{~K}$ & $\begin{array}{l}480 \\
\text { rpm }\end{array}$ \\
\hline
\end{tabular}

As we can see in the Table 1, Ericsson-Brayton engine could have these functional parts: pre-heater, primary heater, cooler and also there can be an external combustion chamber. Our system should work with closed cycle, with dry air as working fluid [4]. The closed cycle enables heat recovery from working fluid, so the regenerated heating power is bigger than in opened cycle, where the most part of heat energy is used to pre-heat the air after compression. We are assuming the temperature of the working fluid after expansion in range from $240{ }^{\circ} \mathrm{C}$ to $320^{\circ} \mathrm{C}$ [4]. For each working fluid, the dry air in the tubes and the exhaust gases outside the tubes, we have set the characteristically temperatures and physical properties. For the formula we use literature [6] and [7]. Main temperature for heat transfer through pipes in bundle is:

$$
\Delta T_{l n}=\frac{\Delta T_{M A X}-\Delta T_{M I N}}{\ln \frac{\Delta T_{M A X}}{\Delta T_{M I N}}}
$$

The difference if the tubes are straight or staggered, or partly staggered, is characterized with dimensionless constants.

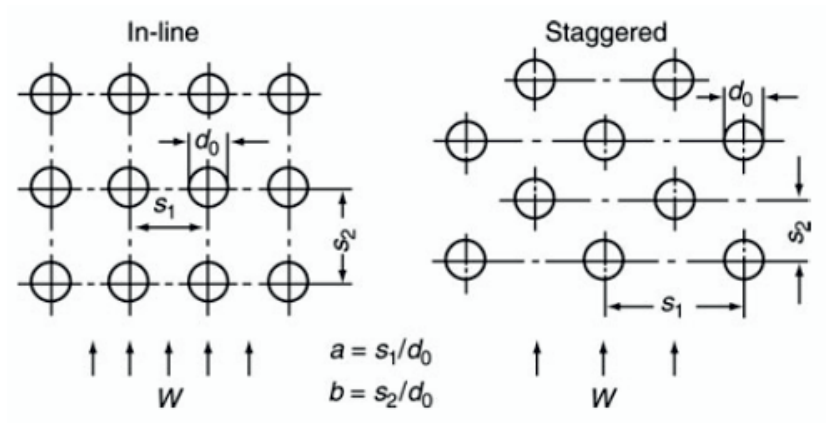

Figure 2. Lateral and longitudinal spacing in tube bundles.

If the tube bundle has horizontal spacing " $\mathrm{s}_{1}$ " and vertical spacing "s ${ }_{2}$ ", we can characterize the bundle with these constants:

$$
\begin{gathered}
a=\frac{s_{1}}{d_{0}} \\
b=\frac{s_{2}}{d_{0}} \\
\psi=1-\frac{\pi}{4 . a}
\end{gathered}
$$

Also we can define the streamed length "l", that can be expressed as length of flow path transversed over a single tube [7]:

$$
l=\frac{\pi}{2} \cdot d_{o}
$$


Another difference can we see in the non-dimensional criteria. Reynolds number is characterizing the flowing medium and the type of flow. It depends on flow velocity and also on the geometry. For heat transfer through tubes in bundle we can use following Reynolds number criteria:

$$
R e=\frac{w \cdot l}{\psi \cdot v}
$$

Nusselt number is characterizing the heat transfer. If the turbulence in the inflowing medium is low, deviations in the Nusselt number may occur. The average Nusselt number in a cross-flow over a bundle of smooth tubes can be calculated from that in a cross-flow over a single tube. For our purpose we have used the criteria equation according to [7], [8]. The heat transfer is described by the 2 parts of flow, the turbulent part and the laminar part of the flow near the walls:

$$
\begin{gathered}
N u_{l, l a m}=0,664 \cdot \sqrt{R e_{\psi, l}} \cdot \sqrt[3]{P r} \\
N u_{l, t u r b .}=\frac{0,037 \cdot R e_{\psi, l}^{0,8} \cdot \operatorname{Pr}}{1+2,443 \cdot R e_{\psi, l}^{-0,1} \cdot\left(\operatorname{Pr}^{2} / 3-1\right)}
\end{gathered}
$$

Turbulent flow in pipe sets in at $\operatorname{Re}>10^{4}$. In the transition region of Reynolds number from 2300 to $10^{4}$ the type of flow is also influenced by the nature of inlet stream and the form of pipe inlet. Tube bundles with inline tubes behave more like paralell chanels, which are formed by the tube rows. An expected increase in heat transfer coefficient due to the turbulence enhancement caused by the tube rows does not occur [7].

Our aplication for hot air Ericsson-Brayton engine will use as primary heat exchanger tube heat exchanger with staggered tubes. For this type of heat transfer through tube bundle we can define, according to [7], the average Nusselt number for bundle:

$$
N u_{0, \text { bundle }}=\frac{1+(n-1) \cdot f a}{n} \cdot N u_{l, 0}
$$

where:

$$
\begin{gathered}
f_{a, \text { stag }}=1+\frac{2}{3 b} \\
N u_{l, 0}=0,3+\sqrt{N u_{l, l a m+}^{2} N u_{l, t u r b}^{2}}
\end{gathered}
$$

Then followed the estimation of overall coefficient of heat transfer that is depending on the Nusselt number.

$$
\alpha=\frac{N u_{\text {bundle }} \cdot \lambda_{T M}}{l}
$$

The overall coefficient of heat transfer was set for both mediums and for wall is known the coefficient of thermal conductivity. When we know both sides of equation, we can compare them together and estimate the overall heat transfer coefficient and the needed heat transfer surface. After this we have proceed to creation of 3D model of the exchanger. The model was in first step created with wall thickness of tubes and inlet tube.

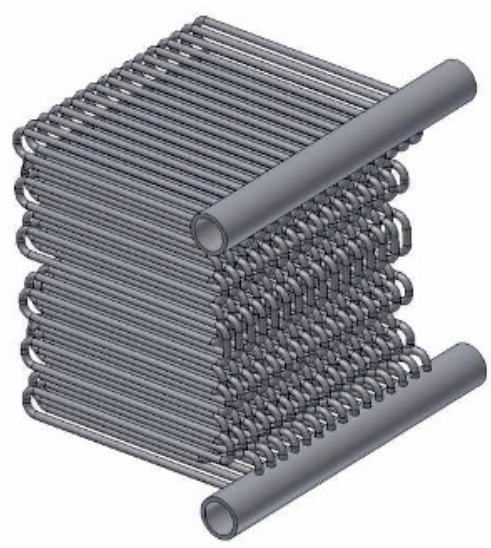

Figure 3. 3D model of proposed heat exchanger.

But this solution sets major requirements on computing hardware, so we have decided to create a simplified model with tubes as full material and only set the right material constants for the surfaces.

\section{Heat exchanger verification using Ansys Fluent}

The model for Ansys Fluent was created using 3D modeling software. Very important by the creation of model was substitute all the construction elements by simple geometrical features. This means, that the whole exchanger was modeled as one volume with tubes as full material. The tubes have multiple collectors at inlet and outflow. No construction tolerances are reflected. The exteriour of the heat exchanger was created by cutting out material from volume. The model was solved with polyhedral mesh and K- $\varepsilon$ model. In Figure n. 4 we can see detail of meshed volume of the heat exchanger.

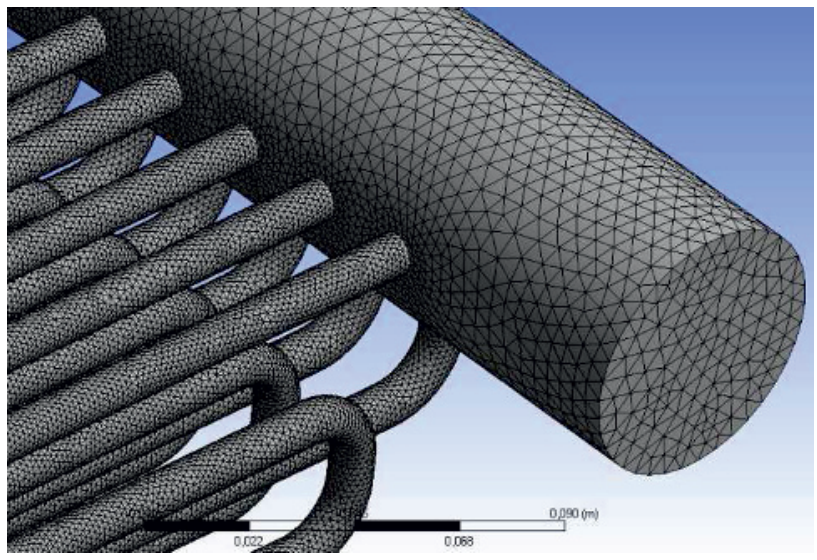

Figure 4. Mesh in proposed heat exchanger volume. 
The mesh was created with enabled curvature on elements. The flow was predicted as turbulent. In the Figure 5 we can see the temperature fields. Monitored were inlet and output pipes temperature, that is depending on the overall heat transfer. Monitored was the temperature input and output pipes, which is depending on the total heat transfer. In the mathematical model we assumed the flue gas temperature, which heats the air, at $700{ }^{\circ} \mathrm{C}$. The outlet temperature was then computed by program. In the picture we can see the highest temperature of $700^{\circ} \mathrm{C}$, which was given as a boundary condition. In the heat exchanger are visible also the tubes, in which the air is heated. The air outlet is in the underside, where it reaches $616^{\circ} \mathrm{C}$, which is more than was expected. This finding confirmed our estimate of the power reserve of exchanger. Another feature of the proposed structure is also visible in the distribution of temperature fields. Fields with a high temperature around the edges of exchanger revealed increased gas flow around the heat exchange surfaces, which in this case is undesirable and it is required partly change design of the exchanger to guide the flow of flue gas directly between the tubes.

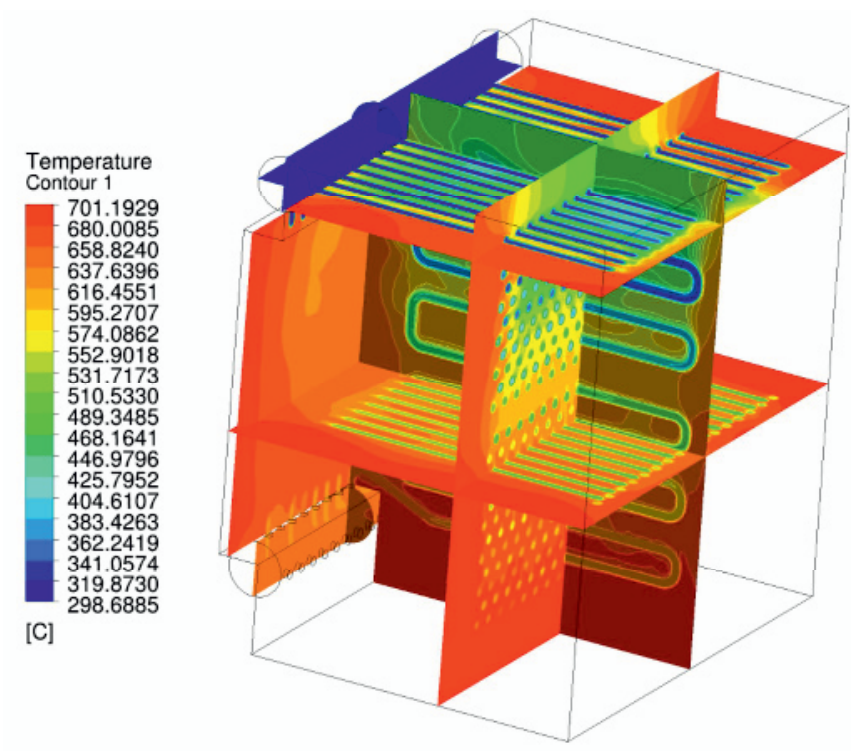

Figure 5. Temperature fields in proposed heat exchanger.

Another monitored parameter was the flow velocity between tubes. This is presented in the Figure n. 6 . apparent defect is in the right side, where the flow reaches doubled velocity as in the remaining volume. Why can this happened? Firstly we thought there are wrong marginal settings, but we discovered there is a mesh error which is caused by inlet tube. In this area mesh is not enough refined so there is some divergence. But in the other volume of exchanger the mesh is regular. The flow between tubes reaches values up to $0.4 \mathrm{~ms}^{-1}$ which is very similar to our proposed flow velocity from the furnace. This velocity has also influence on heat transfer and we have to take some constructional changes to break and reflect the flow to ensure, that the flow will be mostly turbulent.

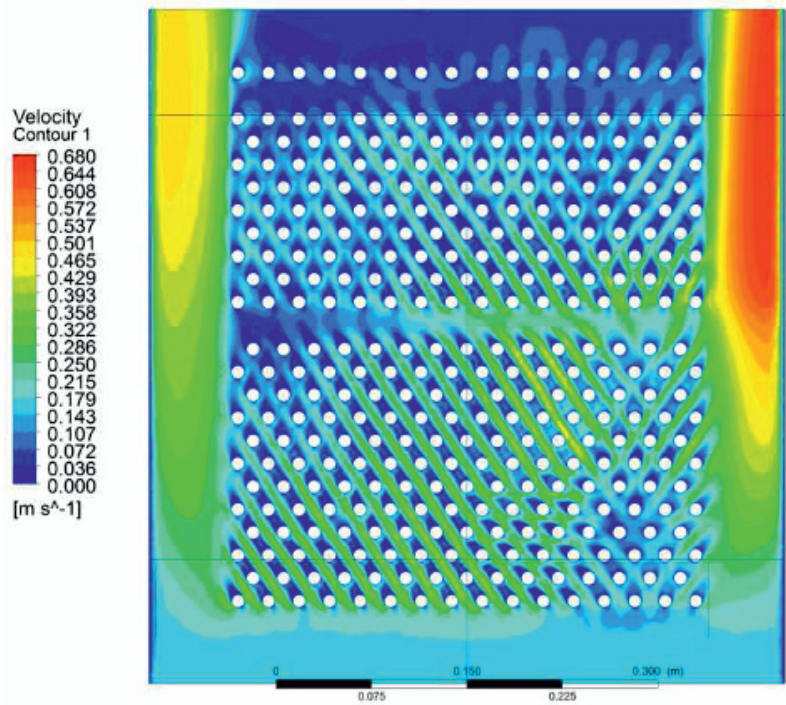

Figure 6.Velocity fields in proposed heat exchanger.

\section{Conclusion}

Heat exchanger design for hot air Ericsson-Brayton engine sets wide range of specifications. We have set basic dimensions using criterion formula. Then followed the calculation using Ansys Fluent. As next step we have to improve our computational model and complete the construction documentation and finish all design fundamentals, so the construction and real measurements can follow.

\section{Acknowledgments}

This work is supported by "Výskum nových spôsobov premeny tepla z OZE na elektrickú energiu využitím nových progresívnych cyklov" ITMS 26220220117.

\section{References}

1. M. Creyx, E. Delacourt, C. Morin, B. Desmet, P. Peultierin, Eur. Phys. J. Energy, 49 (2012)

2. J. Kalčík, K. Sýkora, Technická termodynamika, (1973)

3. S. Bonnet, M. Alaphilippe, Stouffs, International Journal of Thermal Sciences, 44 (2005)

4. P. Durčanský, J. Jandačka, A. Kapjor, Š, Papučík, SKMTaT, (2013)

5. J. Hužvár, P. Nemec, Materials science and technology, (2011)

6. P. Stehlík, a kol., Tepelné pochody, výpočet výmenníku tepla, (1991)

7. Verein Deutscher Ingenieure, VDI heat atlas, Heidelberg Springer-Verlag, Berlin, (2010)

8. R. Lenhard, M. Malcho, Mathematical and Computer Modelling, 57 (2013) 